Kong. Res. J. 1(1) : 31-34, 2014

Kongunadu Arts and Science College, Coimbatore

\title{
A SIMPLE, EFFICIENT, ONE-POT THREE-COMPONENT DOMINO SYNTHESIS OF HANTZSCH 1,4- DIHYDROPYRIDINE UNDER MILD CONDITIONS
}

\author{
Amuthavalli, $A^{*}$ and R. Velmurgan \\ Department of Chemistry, Kongunadu Arts and Science College, Coimbatore. \\ *Email-amuthavallia@gmail.com
}

\begin{abstract}
A series of substituted Hantzsch 1, 4-Dihydropyridine derivatives were synthesized and the structures of these compounds were established on the basis of analytical and spectral data such as FT-IR and ${ }^{1} \mathrm{H}$-NMR. The advantages of this system are one-step procedure, high yields of the products and the ability to carry out large-scale reactions.
\end{abstract}

Keywords: Hantzsch reaction, 1,4-dihydropyridines, cyclization, one-pot procedure.

\section{INTRODUCTION}

Multicomponent reactions (MCRs) are onepot processes that combine three or more substrates simultaneously (Guillena, et al., 2007). Such processes are of great interest in diversity-oriented synthesis, especially to generate compound libraries for screening purposes.

Dihydropyridine (DHP) is a molecule based up on pyridine, and the parent of a class of molecules that have been semi-saturated with two substituent's replacing one double bond. They are particularly well known in pharmacology as L-type calcium channel blockers, used in the treatment of hypertension compared with certain other L-type calcium channel blockers [For example those of the phenyl alkylamine class such as verpamil] which have significant action at the heart, they are relatively vascular selective action at the heart, they are relatively vascular selective in their mechanism of action in lowering blood pressure.

Some of the representative compounds of this class possess acaricidal, insecticidal, bactericidal and herbicidal activities (Kawase et al., 2002). It has been recognized as vital drugs in the treatment of angina and hypertension (Janis and Triggle, 1983; Boecker and Guengerich, 1986). Some of them have been commercialized and it has been proven that their therapeutic success is related to their efficacy to bind to calcium channels and consequently to decrease the passage of the trans membrane calcium current, associated in smooth muscle with a long lasting relaxation and in cardiac muscle with a reduction of contractility throughout the heart (Bossert et al., 1981; Love et al., 1974).

In addition DHP finds applications in stereo specific hydrogen transfer reactions. Krechi and Smrckova have reported stereo-specific reduction of phenyl glyoxylic and pyruvic acid using DHP to biomimetic models of lactase dehydrogenase. Recently, dihydropyridines are used as organo catalysts for asymmetric reactions such as hydrogenation of quinolines in the synthesis of alkaloids (Rueping et al., 2006), asymmetric reductive amination of aldehydes (Hoffmann et al., 2006) and hydrogenation of $\alpha, \beta$,unsaturated aldehydes and ketones, (Martin and List, 2006), recent studies suggest several other medicinal applications including neurotropic, antidiabetic, membrane protecting, as well as anticancer, antibacterial, and antiviral activities.

Development of an efficient and versatile method for the preparation of 1,4-dihydropyridines is an active ongoing research area (Bocker and Guengerich, 1986; Breitenbucher and Figliozzi 2000; Gordeev et al., 1996; Vanden Eynde and Mayence, 2000) and there is scope for further improvement toward synthesis of new derivatives of 1,4-dihydropyridines with milder reaction conditions and improved yields. Therefore, we decided to synthesize new derivatives of 1,4-dihydropyridines and provide a clean and easy work-up.

\section{EXPERIMENTAL}

All chemicals were purchased from SigmaAldrich, India. The reactions were monitored by TLC. The products were isolated and identified by comparison of their physical and spectral data. IR spectra of the products were recorded on shimadzu spectrometer in the range $500-4000 \mathrm{~cm}^{-1}$. ${ }^{1} \mathrm{H}$ NMR spectra were recorded using $\mathrm{CDCl}_{3}$ as solvent chemical shifts were expressed in ' $\delta$ ' units (ppm) and quoted downfield from TMS as internal standard by the instrument :Bruker Avance III

\section{SYNTHESIS OF HANTZSCH 1,4- DIHYROPYRIDINE:}

A mixture of substituted benzaldehyde (1) (1 $\mathrm{mmol})$, $\beta$-dicarbonyl (2) (2mmol), ammonium acetate (3) 
(3mmol) and ethanol $(10 \mathrm{ml})$ were successively changed in to $100 \mathrm{ml}$ round bottom flask. Then the reaction mixture was heated in a water bath for 5 hours at $100^{\circ} \mathrm{C}$ and a yellow colour product was gradually formed (scheme-1). The completion of reaction is tested by thin layer chromatography [TLC] the resulting product $(4 \mathrm{a}-4 \mathrm{l})$ was recrystallized with ether.

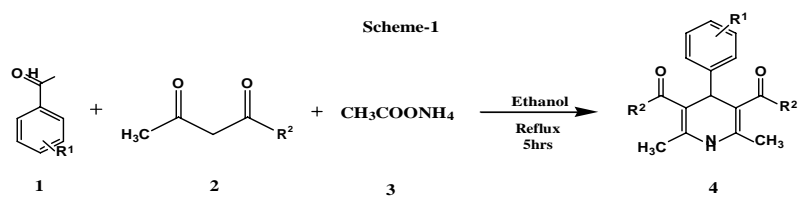

\section{RESULTS AND DISCUSSION:}

Various 1,4-dihydropyridine derivatives were synthesized. In all the cases, the desired protect were obtained in high yields. Mechanistically, this reaction is a complex reaction as it involves three reactants at differing stoichiometry. There could be two reaction pathways to obtain 1,4-dihydropyridine: (1) The reaction may go through aldol condensation of $\beta$ dicarbonyl with benzaldehyde and subsequent reaction of aldol with enamine (obtained through condensation of one molecule of $\beta$-dicarbonyl with $\mathrm{NH}_{4} \mathrm{OAc}$ ) or (2) The reaction may go through condensation of two molecules of $\beta$-dicarbonyl with $\mathrm{NH}_{4} \mathrm{OAc}$ forming an imine which subsequently undergoes condensation with benzaldehyde to form 1,4-dihydropyridine. Both electro-rich and electrondeficient aromatic aldehydes worked well. Many of the pharmacologically significant substitution patterns can be introduced with good efficiency. (Table-1)

\subsection{Spectral data for selected products:}

3,5-diethyl-2,6-dimethyl-4-(2,3-dichlorophenyl)-1,4dihydropyridine-3,5-dicarboxylate. $(4 \mathrm{~d})$ IR $\cup\left(\mathrm{cm}^{-1}\right)=$ $3332.14,1732.15,1566,1098.51,730,648.11 ;{ }^{1} \mathrm{H}$ NMR $\left(\mathrm{CDCl}_{3}\right) \delta(\mathrm{ppm})=1.20-1.16(\mathrm{t}, 6 \mathrm{H})$, $2.41(\mathrm{~s}, 6 \mathrm{H}), 4.10-$ $4.04(\mathrm{q}, 4 \mathrm{H}), 4.95(\mathrm{~s}, 1 \mathrm{H}), 5.64(\mathrm{~s}, 1 \mathrm{H}), 7.31-7.22(\mathrm{~m}, 3 \mathrm{H})$

3,5-diethyl-2,6-dimethyl-4-(2-nitrophenyl)-1,4dihydropyridine-3,5-dicarboxylate. (4e) IR $\cup\left(\mathrm{cm}^{-1}\right)=$ 3336.9, 1727.3, 1645.35, 1548.9, 1207.49, 1122.62, 733.95; ${ }^{1} \mathrm{H} \mathrm{NMR}\left(\mathrm{CDCl}_{3}\right) \delta(\mathrm{ppm})=1.23-1.19(\mathrm{t}, 6 \mathrm{H})$, $2.32(\mathrm{~s}, 6 \mathrm{H}), 4.10-$

4.06(q,4H),4.98(s,1H),5.64(s,1H),7.28-7.09(m,4H)

2,3,5,6-tetramethyl-4-(4-methoxyphenyl)-1,4dihydropyridine-3,5-dicarboxylate.(4l)

IR $\cup\left(\mathrm{cm}^{-1}\right)=3348.57,1693.57,1493.93,1436.07$, $1218.10,748.41,680.90 ;{ }^{1} \mathrm{H} \mathrm{NMR}\left(\mathrm{CDCl}_{3}\right) \delta(\mathrm{ppm})=$ 2.32(s,6H),
3.64(s,6H),3.74(s,3H),4.94(s,1H),5.62(s,1H),6.73$7.18(\mathrm{~m}, 4 \mathrm{H})$

\section{CONCLUSION}

In conclusion, we have developed a simple and efficient synthetic protocol for the synthesis of a wide variety of Hantzsch 1,4-dihydropyridine derivatives. Mild reaction conditions, cost efficiency, simplicity in operation, and large-scale applicability are some significant features of this protocol. There is a wide scope to develop enamine chemistry from these molecules with electron deficient systems or cyclization. This can lead to excellent new molecules for further biological evaluations.

\section{REFERENCES}

Bocker, R.H and F.P Guengerich (1986). Oxidation of 4-aryl- and 4-alkyl-substituted 2,6-dimethyl3,5-bis(alkoxycarbonyl)-1,4-dihydropyridines by human liver microsomes and immunochemical evidence for the involvement of a form of cytochrome P-450. J. Med. Chem 29: 1596-1603.

Bossert, F., H. Meyer and E. Wehinger (1981). 4Aryldihydropyridines, a new class of highly active calcium antagonists. Angew. Chem. Int. Ed. Engl 20: 762-770.

Breitenbucher, J.G. and G. Figliozzi (2000). Solidphase synthesis of 4-aryl-1,4-dihydropyridines via the Hantzsch three component condensation. Tetrahedron Lett. 41: 4311-4319.

Gordeev, M.F., D. V. Patel and E.M. Gordon (1996). Approaches to combinatorial synthesis of heterocycles: a solid-phase synthesis of 1,4dihdropyridines. J. Org. Chem. 61:924-929.

Guillena, G., D.J. Ramon and M. Yus. (2007). Enantioselective direct aldol reaction: the blossoming of modern organocatalysis. Tetrahedron Asymmetry. 18: 693-700.

Hoffmann, S., M. Nicoletti and B. List. (2006). Catalytic asymmetric reductive amination of aldehydes via dynamic kinetic resolution. J. Am. Chem. Soc 128:13074-13081.

Janis, R.A. and D.J. Triggle. (1983). New developments in calcium ion channel antagonists. J. Med. Chem 26: 77-85.

Kawase, M., A. Shah, H. Gaveriya, N. Motohashi, H. Sakagami, A. Varga, and Molnar, (2002). 3, 5dibenzoyl-1, 4-dihydropyridines: synthesis and MDR reversal in tumor cells J. Bioorg. Med. Chem 10: 1051-1057. 
Love, B., M. Goodman, K. Snader, R. Tedeschi and E. Macko. (1974). Hantzsch-type dihydropyridine hypotensive agents. J. Med. Chem 17:956-962.

Martin, N.J.A. and B. List (2006). Highly enantioselective transfer hydrogenation of $\alpha, \beta$ unsaturated ketones. J. Am. Che. Soc. 128: 13368-13375.

Rueping, M., A.P. Antonchick and T. Theissmann, (2006). A highly enantioselective brønsted acid catalyzed cascade reaction: organocatalytic transfer hydrogenation of quinolines and their application in the synthesis of alkaloids'. Angew. Chem. Int. Ed. 45: 3683-3690.

Vanden Eynde, J.J and A.Mayence. (2000). New methodologies for the preparation of drugs and their metabolites. Application to 1,4dihydropyridines structurally related to calcium channel modulators of the Nifedipinetype. Intl. J. Med. Biol. Environ. 28: 25-32.

Table-1-Analytical data for 1,4-dihydropyridine derivatives

\begin{tabular}{|c|c|c|c|c|c|}
\hline Entry Products & $\mathbf{R}^{1}$ & $\mathbf{R}^{2}$ & Products & Yielda (\%) & Melting point (ㅇ) \\
\hline $4 a$ & $\mathrm{C}_{6} \mathrm{H}_{5}$ & OEt & & 79 & 175 \\
\hline $4 b$ & $2-\mathrm{Cl}-\mathrm{C}_{6} \mathrm{H}_{4}$ & OEt & & 74 & 143 \\
\hline $4 c$ & $4-\mathrm{Cl}-\mathrm{C}_{6} \mathrm{H}_{4}$ & OEt & & 79 & 160 \\
\hline $4 d$ & 2,3-di-Cl- $\mathrm{C}_{6} \mathrm{H}_{4}$ & OEt & & 78 & 145 \\
\hline $4 e$ & $2-\mathrm{NO}_{2}-\mathrm{C}_{6} \mathrm{H}_{4}$ & OEt & & 74 & 174 \\
\hline 4f & $2-\mathrm{OMe}-\mathrm{C}_{6} \mathrm{H}_{4}$ & OEt & & 75 & 168 \\
\hline $4 \mathrm{~g}$ & $\mathrm{C}_{6} \mathrm{H}_{5}$ & $\mathrm{OMe}$ & & 79 & 165 \\
\hline
\end{tabular}


Table 1 Analytical data for 1,4-dihydropyridine derivatives (Continued)

\begin{tabular}{|c|c|c|c|c|c|}
\hline Entry Products & $\mathbf{R}^{\mathbf{1}}$ & $\mathbf{R}^{2}$ & Products & Yielda $(\%)^{2}$ & Melting point $\left({ }^{\circ} \mathrm{C}\right)$ \\
\hline $4 h$ & $2-\mathrm{Cl}-\mathrm{C}_{6} \mathrm{H}_{4}$ & $\mathrm{OMe}$ & & 78 & 168 \\
\hline $4 i$ & $4-\mathrm{Cl}-\mathrm{C}_{6} \mathrm{H}_{4}$ & $\mathrm{OMe}$ & & 72 & 150 \\
\hline $4 \mathbf{j}$ & 2,3-di-Cl- $\mathrm{C}_{6} \mathrm{H}_{4}$ & $\mathrm{OMe}$ & & 79 & 172 \\
\hline $4 k$ & $2-\mathrm{NO}_{2}-\mathrm{C}_{6} \mathrm{H}_{4}$ & $\mathrm{OMe}$ & & 78 & 124 \\
\hline 41 & 4-OMe- $\mathrm{C}_{6} \mathrm{H}_{4}$ & $\mathrm{OMe}$ & & 75 & 180 \\
\hline
\end{tabular}

a- Isolated yields. 